\title{
Criteria for EASO-Collaborating Centres for Obesity Management
}

\author{
Constantine Tsigos $^{\mathrm{a}}$ Vojtech Hainer ${ }^{\mathrm{b}} \quad$ Arnaud Basdevant $^{\mathrm{c}} \quad$ Nick Finer $^{\mathrm{d}}$ \\ Elisabeth Mathus-Vliegen ${ }^{\mathrm{e}}$ Dragan Micic $^{f}$ Maximo Maislos $^{\mathrm{g}}$ Gabriela Roman $^{\mathrm{h}}$ Yves Schutz $^{\mathrm{i}}$ \\ Hermann Toplak ${ }^{j}$ Volkan Yumuk ${ }^{k}$ Barbara Zahorska-Markiewicz', for the Obesity Management \\ Task Force of the European Association for the Study of Obesity
}

${ }^{\text {a }}$ Department of Endocrinology, HYGEIA Hospital, Athens, Greece

${ }^{\mathrm{b}}$ Obesity Management Centre, Institute of Endocrinology, Prague, Czech Republic

${ }^{c}$ Department of Endocrinology, Pitié Salpêtrière Hospital; Pierre and Marie Curie-Paris 6 University, Paris, France

${ }^{\mathrm{d}}$ University College London Hospitals, London, UK

e Department of Gastroenterology and Hepatology, Academic Medical Centre, University of Amsterdam, Amsterdam, the Netherlands

f Department for Obesity, Metabolic and Reproductive Disorders, Clinic for Endocrinology, Diabetes and Diseases of Metabolism,

Clinical Center of Serbia, Faculty of Medicine, University of Belgrade, Belgrade, Serbia

${ }^{9}$ Atherosclerosis and Metabolism Unit, Soroka UMC, Ben-Gurion University SHC, Beer Sheva, Israel

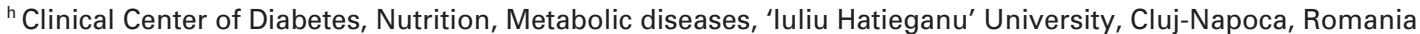

' Department of Physiology, University of Lausanne, Lausanne, Switzerland

j Department of Medicine, Medical University, Graz, Austria

${ }^{k}$ Department of Medicine, Division of Endocrinology and Metabolism, Istanbul University Cerrahpasa Medical Faculty, Istanbul, Turkey

' Department of Pathophysiology, Medical University of Silesia, Katowice, Poland

\section{Keywords}

European criteria - Obesity management centres .

European Association for the Study of Obesity · EASO .

Obesity Management Task Force - OMTF

\section{Summary}

Obesity is recognised as a global epidemic and the most prevalent metabolic disease world-wide. Specialised obesity services, however, are not widely available in Europe, and obesity care can vary enormously across European regions. The European Association for the Study of Obesity (EASO, www.easo.org) has developed these criteria to form a pan-European network of accredited EASO-Collaborating Centres for Obesity Management (EASO-COMs) in accordance with accepted European and academic guidelines. This network will include university, public and private clinics and will ensure that the obese and overweight patient is managed by a holistic team of specialists and receives comprehensive state-ofthe-art clinical care. Furthermore, the participating centres, under the umbrella of EASO, will work closely for quality control, data collection, and analysis as well as for education and research for the advancement of obesity care and obesity science.

\section{Introduction}

Obesity is now recognised as the most prevalent metabolic disease world-wide, affecting not only adults but also children and adolescents [1]. The World Health Organisation has long declared obesity a global epidemic [2] impacting a huge burden on health and health costs [3-5]. In the majority of European countries, overweight and obesity affect $50 \%$ of the population (fig. 1) and are responsible for about $80 \%$ of cases of type 2 diabetes, $35 \%$ of ischaemic heart disease and $55 \%$ of hypertensive disease among adults, which together cause more than 1 million deaths and 12 million life-years of ill health each year $[1,3,5,6]$.

Despite steady progress in the management of obesity, its prevalence continues to rise, stressing the necessity for prevention and intervention strategies not only at the individual level but also at the communities and the population as a whole [1,6-8]. Specialised obesity services, however, are not widely available. In some countries they have been established only in large hospitals and/or academic units with clinical and research interest in this field, which serve quite large populations. In other countries, such units have been established in the private sector, either in hospital or as independent clinics (Obesity Management Task Force (OMTF) of the

\section{KARGER \\ Fax +497614520714 \\ Information@Karger.de}

www.karger.com (c) 2011 S. Karger GmbH, Freiburs

$1662-4025 / 11 / 0044-0329 \$ 38.00 / 0$

Accessible online at:

www.karger.com/ofa
Constantine Tsigos, $\mathrm{MD}, \mathrm{PhD}$

EASO OMTF

113-119 High Street, Hampton Hill, Middlesex, TW12 1NJ, UK

Tel. +442087832256 , Fax +44 7789818039

ctsigos@gmail.com 
Fig. 1. Prevalence of overweight and obesity in Europe (source: International Obesity Task Force (IOTF)).
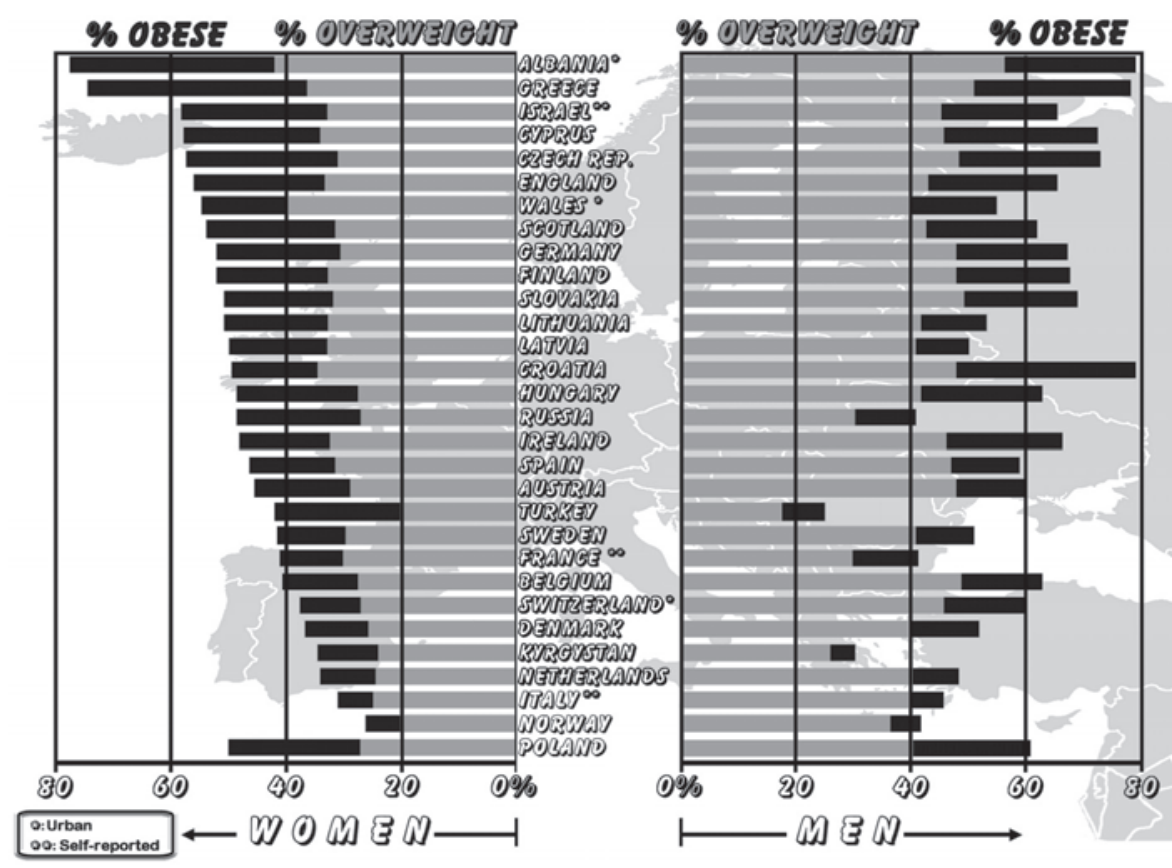

European Association for the Study of Obesity (EASO), unpublished data). In any case, access to these specialised obesity units is not easily available to all those obese patients that require evaluation and treatment.

A major problem is that the provision of care for the overweight and the obese varies greatly among the European regions and countries. Furthermore, there remain many unresolved issues in obesity management in Europe, with several problems identified, for example:

- discrimination and stigmatisation of the obese persons

- poor information for patients about medical consequences of obesity and what treatments are effective and available

- delay in patients seeking medical and preventive care and clinicians referring to specialists when indicated

- lack of availability and visibility of, and accessibility to health resources in obesity medicine

- lack of knowledge and training in accommodating the physical and emotional needs of obese persons among physicians and other health care providers

- incomplete multidisciplinary teams

- lack of collaboration between physicians and surgeons specialised in obesity management

- lack of medical equipment appropriate to patient size: e.g. blood pressure cuff, beds, and nuclear magnetic resonance (NMR) imaging devices

- perception that obesity medicine is limited to weight loss and that health cannot be improved unless weight loss is obtained

- lack of sustainable follow-up

- lack of formalised recognition of which obesity management services meet minimum standards.

Thus, the EASO (www.easo.org) decided to develop criteria for EASO-Collaborating Centres Specialised in Obesity Management (EASO-COMs) in an effort to address the need for establishing relatively uniform state-of-the-art standards for specialised obesity care across Europe. The working group of the OMTF of the EASO that performed this task was composed of experts, representing key disciplines in comprehensive obesity management and reflecting European geographical diversity. This group has already produced European guidelines for obesity management in adults and for surgery management of severe obesity in collaboration with the European Chapter of the International Federation for the Surgery of Obesity (IFSO-EC) [9, 10].

\section{EASO Goals - Mission of EASO-Collaborating Centres for Obesity Management}

Our aim was to provide physicians, health-care policy makers, and health-care providers with authoritative criteria for the development of obesity management centres across Europe that are recognised by the health authorities. This set of criteria will also facilitate the development of a pan-European network of EASO collaborating centres specialised in obesity management that will include university, public and private clinics, which will comply with the EASO requirements and work in close collaboration for the better management of all obese patients (table 1).

In addition to their mission described in table 1 , these EASO-COMs will collaborate with EASO and other European specialist associations for developing consensus statements/guidelines to treat specialised aspects of obesity and/or specialized obesity groups. They will also be able to develop 
Table 1. Mission of EASO-COMs

- Implement state-of-the art evidence based care for obese patients

- Monitor all obesity related medical conditions and risk factors

- Provide high quality patient and public information

- Improve access to care pathways by optimising referral processes and developing close working between levels of care

- Develop comprehensive multidisciplinary local collaboration

- Facilitate, and empower patients to make healthy lifestyle changes: develop therapeutic education

- Educate staff about treating patients with obesity

- Encourage development of and support patient associations by sharing experience and expertise

- Offer or collaborate with preventive care services

- Promote obesity related knowledge and awareness among the public and health care providers

- Improve the collaboration interface between clinical researchers and scientists

- Integrate health care, teaching, and research

- Facilitate clinical research projects

- Contribute to a network of EASO-COMs across Europe with close collaboration and communication

protocols (that can be country-tailored) for evaluation of obese patients that could be used by all physicians managing obese patients.

\section{Requirements for EASO-Collaborating Centres for Obesity Management}

EASO-COMs should adhere to EASO/OMTF guidelines for obesity management $[9,10]$ and should fulfil the following criteria:

\section{Patients}

The EASO-COM should not operate a selective policy for seeing patients and accept all referred obese patients, including persons with severe or extreme obesity (BMI $\geq 40 \mathrm{~kg} / \mathrm{m}^{2}$ ), complex obesity, and obesity related to rare diseases. Each centre should receive more than 100 new obese patients per year and should also provide care for overweight and obese children and adolescents, including family oriented interventions. Thus, it is recommended to have collaborating paediatrician(s) and competence for family treatment.

\section{Facility Location}

The EASO-COM may comprise one or more facilities or sites, but they should function as a unit and be closely geographically located.

\section{Staff Specifications}

All staff should have proven advanced knowledge, skills, and competence in obesity management and clinical research. The medical team must be trained in accommodating the emo- tional needs of persons who are obese. Clinical and scientific staff of the centres are expected to be members of EASO through national associations. A multidisciplinary team should work closely together, particularly when dealing with complex medical situations and bariatric surgery decisions. Continuing medical education will be required for all members of the team. The team should include:

- physicians with special training in obesity management e.g. SCOPE fellows or other physicians with comparable knowledge, skills and competence as documented by a structured $\mathrm{CV}$; specific clinical research experience and training are also expected

- registered dietitian(s) and/or nutrition therapists with proven experience in obesity management

- behavioural therapist/psychologist/psychiatrist/social worker with proven experience in obesity management

- exercise physiologist/physiatrist with proven experience in obesity management

- nurses or other staff specifically trained for managing obese patients, e.g. consultation and examinations, such as calorimetry, anthropometry, including body composition assessment and counselling for surgery.

The EASO-COM should be able to receive and manage patients with severe obesity and offer them obesity surgery, where appropriate, through its own or affiliated bariatric facilities (accredited whenever possible), as described below.

\section{Links to General Practitioners}

Patient pathway management is a key issue. Easy access to specialised obesity care is very important and requires a referral process that allows closer working between levels of care.

\section{Links to Other Medical Services and Facilities}

The EASO-COM should have links and support from a large spectrum of medical services and facilities, such as paediatrics, endocrinology, medical genetics, gastroenterology, surgery, pulmonology, sleep specialists, oncology, cardiology, intensive care, psychiatry, orthopaedics, obstetrics and gynaecology, specialized exercise facilities, and self-help groups.

\section{Equipment and Tools Appropriate for Obese Patients}

Specific protocols are necessary for patient evaluation. Equipment and tools employed are divided into essential ones that are obligatory, recommended ones that would enhance the competence of the centre, and optional ones that can be used for examination of uncommon cases of altered body composition and for clinical research purposes (table 2).

\section{Treatment Modalities}

Patient treatment of obesity should be based on good clinical care and evidence-based interventions $[9,10]$. The management and treatment of obesity have wider objectives than weight loss alone and include treatment of obesity related complications (e.g. sleep apnoea, hypertension, etc.), risk re- 
Table 2. Equipment and tools (geared for obese patients)

Essential

Appropriate cuffs for blood pressure measurement $(>34 \mathrm{~cm})$

Scales with adequate weight capacity (>200 kg)

Armless chairs, high firm sofas in waiting rooms

Wide examination tables

Beds for very obese patients $>200 \mathrm{~kg}$

Stretchers adapted to very obese persons

Sleep apnoea monitors on site or at affiliated facilities

Food frequency questionnaire and/or dietary intake recording and assessment

Questionnaires concerning depression, eating attitudes and disorders, physical activity, and QoL

Access to accredited hormonal and molecular genetics laboratories Access to additional relevant diagnostic procedures, such as X-ray, ultrasound, CT and NMR scanning, endoscopy, cardiac and pulmonary assessment, and nuclear medicine, adapted to the very obese persons

\section{Recommended}

Pedometers

Skinfold calipers

Body composition analysis (bio-impedance, dual-energy X-ray absorptiometry (DEXA))

Indirect calorimetry

Optimal

Hydrodensitometry

Air displacement plethysmography

duction, and health improvement. Psychological and social issues are major therapeutic objectives. In addition to weight management, appropriate management of obesity complications is also essential and should be provided for the patient, including management of dyslipidaemia, optimising glycaemic control in type 2 diabetic patients, controlling hypertension as well as management of psychosocial disturbances, pulmonary disorders, and musculoskeletal problems [9-11].

Treatment should be individually tailored [12]. Each EASO-COM should be able to provide a wide spectrum of clinically proven treatment options and combinations of them, for example:

- individual or group lifestyle modification

- nutritional advice, including but not limited to very low calorie diets (VLCDs) and meal replacement therapies

- physical activity modification

- cognitive-behavioural therapy

- psychological support

- anti-obesity drugs

- bariatric surgery

- emerging techniques under scientific assessment.

\section{Educational Tools}

Each EASO-COM should provide a variety of educational opportunities and options for the overweight and obese patient, including:
- individual and/or group educational sessions (include family members where appropriate)

- printed information available for patients and patient groups

- additional tools for education and follow up (phone links, e-mail links, internet links)

- education should be continuous and updated, according to current guidelines.

\section{Affiliation with an Accredited Bariatric Surgery Centre}

A decision to offer surgery should always follow a comprehensive interdisciplinary assessment. The core team providing such assessment should optimally consist of specialists, experienced in obesity management and bariatric surgery. The bariatric surgery centre, whether part of or affiliated to the EASO-COM (accredited by appropriate national or international authorities) should offer laparoscopic food limiting (e.g. adjustable banding, sleeve gastrectomy) and energy absorption limiting operations (e.g. Roux-en-Y gastric bypass, biliopancreatic diversion) as well as corrective plastic surgery [13]. Selection, choice of technique, and follow-up of patients should be performed according to published EASO/IFSO criteria [10].

\section{Data Collection and Management (Use of Database)}

The use of consistent reliable equipment for data collection and the use of a comprehensive database by all EASO-COMs is essential for data management, research, and analysis. This will create an ideal field for collaborative European projects and clinical trials, as ability to recruit patients, assess them, and monitor them will be greatly facilitated. More specifically, it will allow to:

- track outcomes - change in weight, waist circumference, nutritional status, comorbidities, quality of life (QoL)

- avoid loss of follow-up and determine retention rates

- conduct quality control, audit, and research

- communicate with other physicians and national and other European centres.

All EASO-COMs should demonstrate commitment to active involvement in audit, including surgical care, patient followup and outcome assessment, as well as to work within the planned European network of such centres. They should also offer possibilities for external experts to visit and exchange ideas and experience as well as to organise or participate in post-graduate education of physicians and other health care professionals in obesity management.

\section{Education and Training}

EASO-COMs should be responsible for continuous postgraduate obesity education of physicians and other health professionals at national or regional level.

\section{Research}

The EASO-COMs should be in position to engage in clinical research projects, particularly relating to new therapeutic 
medical and surgical interventions. Basic research is also encouraged in collaboration with universities and other research institutions.

\section{Conclusion}

The dramatic increase in the prevalence of overweight and obesity with the consequent impact on health and health costs necessitates the development of specialised obesity centres, where the quality and efficacy of the care offered to these patients are of the highest standards. By establishing these criteria, EASO wishes to establish a European network of EASOcollaborating centres for obesity management that will offer state-of-the-art care for the obese and overweight and at the same time work closely for quality control, data collection, and analysis as well as for education and research.

For further information, please visit www.easo.org.

\section{References}

1 James WP: The epidemiology of obesity: the size of the problem. J Intern Med 2008;263:336-352.

2 World Health Organization: World Health Report 2002. Geneva, WHO, 2003. Available from $w w w$. who.int/whr/2002/en/ (accessed January 2011).

3 Kopelman P: Health risks associated with overweight and obesity. Obes Rev 2007;8(suppl 1):13-17.

4 Trogdon JG, Finkelstein EA, Hylands T, Dellea PS, Kamal-Bahl SJ: Indirect costs of obesity: a review of the current literature. Obes Rev 2008;9:489-500.

$\checkmark 5$ Allender S, Rayner M: The burden of overweight and obesity-related ill health in the UK. Obes Rey 2007;8:467-473

6 Walter S, Kunst A, Mackenbach J, Hofman A, Tiemeier H: Mortality and disability: the effect of overweight and obesity. Int J Obes (Lond) 2009;33: 1410-1418.

7 Hammond RA, Levine R: The economic impact of obesity in the United States. Diabetes Metab Syndr Obes 2010;3:285-295.
8 National Institute of Diabetes and Digestive and Kidney Diseases (NIDDK): Medical Care for Obese Patients. US Department of Health and Human Services. www.win.niddk.nih.gov/publications.

9 Tsigos C, Hainer V, Basdevant A, Finer N, Fried M, Mathus-Vliegen E, Micic D, Maislos M, Roman G, Schutz Y, Toplak H, Zahorska-Markiewicz B; Obesity Management Task Force of the European Association for the Study of Obesity: Management of obesity in adults: European clinical practice guidelines. Obes Facts 2008;1:106-116.

10 Fried M, Hainer V, Basdevant A, Buchwald H, Deitel M, Finer N, Greve JW, Horber F, MathusVliegen E, Scopinaro N, Steffen R, Tsigos C, Weiner R, Widhalm K; Bariatric Scientific Collaborative Group Expert Panel: Interdisciplinary European guidelines on surgery for severe obesity. Obes Facts 2008;1:52-59.
11 Flodgren G, Deane K, Dickinson HO, Kirk S, Alberti H, Beyer FR, Brown JG, Penney TL, Summerbell $\mathrm{CD}$, Eccles MP: Interventions to change the behaviour of health professionals and the organisation of care to promote weight reduction in overweight and obese people. Cochrane Database Syst Rev 2010;3:CD000984.

12 Hainer V, Toplak H, Mitrakou A: Treatment modalities of obesity. What fits whom? Diabetes Care 2008;31(suppl 2):S269-277.

13 Melissas J: Safety, quality and excellence in bariatric surgery. Minerva Chir 2009;64:239-252. 